Vol. 11 No. 022020

e-issn : 2622-0148, p-issn : 2087-0035

\title{
LITERATURE REVIEW: PENGARUH RENDAM KAKI AIR HANGAT TERHADAP PENURUNAN TEKANAN DARAH PADA LANSIA
}

Literature Review: Effect Of Warm Water Foot Drinking On Blood Pressure Reduction In Elderly

\author{
Fina Widyastuti1 ${ }^{1}$ Tri Nurhudi Sasono², Nia Agustiningsih ${ }^{3}$ \\ ${ }^{1}$ Mahasiswa STIKes Kepanjen Malang \\ 2,3Dosen STIKes Kepanjen Malang \\ Email : widyastutifina71@gmail.com \\ Nomor Telepon/HP : 0895338072145
}

\begin{abstract}
Abstract: Hypertension is an increase in systolic pressure of more than $140 \mathrm{mmHg}$ and diastolic more than $90 \mathrm{mmHg}$. One method in lowering blood pressure is to use warm foot baths to improve blood circulation, relax muscles, nourish the heart and reduce edema so that it is effective for reducing blood pressure in hypertensive elderly. The purpose of writing this article is to conduct a literature review analysis of the effect of foot baths in warm water as a method for lowering blood pressure in the elderly. Using the literature review method, a national and international literature search obtained from Google Schoolar and Crossref. Which is limited to the last 8 years, from 2012 to 2020 and only 6 journals that meet the criteria for sample inclusion. Furthermore, the article used as a sample is identified in tabular form and discussed descriptively to explain the available methods. Soak the feet of warm water can help lower blood pressure and can relax muscles and joints after doing activities every day.
\end{abstract}

Keywords: soak foot warm water, blood pressure, elderly

\section{ABSTRAK}

Abstrak : Hipertensi merupakan peningkatan tekanan sistolik lebih dari $140 \mathrm{mmHg}$ dan diastolik lebih dari $90 \mathrm{mmHg}$. Salah satu metode dalam menurunkan tekanan darah yaitu menggunakan rendam kaki air hangat untuk melancarkan sirkulasi darah, relaksasi otot, menyehatkan jantung dan mengurangi edema sehingga efektif untuk penurunan tekanan darah pada lansia yang mengalami hipertensi. Tujuan penulisan artikel ini adalah melakukan analisis literature review terhadap pengaruh rendam kaki air hangat sebagai metode untuk menurunkan tekanan darah terhadap lansia. Menggunakan metode literature review, yaitu sebuah pencarian literature baik nasional maupun internasional yang diperoleh dari google schoolar dan Crossref. Yang dibatasi 8 tahun terakhir, dari tahun 2012 hingga 2020 dan hanya 6 jurnal yang sesuai dengan kriterian inklusi sample. Selanjutnya artikel yang dipakai sebagai sampel ini diindentifikasi dalam bentuk tabel serta dibahas secara deskriptif untuk menjelaskan metode yang ada. Rendam kaki air hangat dapat membantu menurunkan tekanan darah serta dapat merilekskan otot-otot dan persendian setelah melakukan aktivitas setiap hari.

Kata Kunci : Rendam kaki air hangat, Tekanan darah, Lansia

\section{PENDAHULUAN}

Hipertensi di indonesia masih sangat tinggi menurut data iskesdas 201863 juta penduduk indonesia menyandang hipertensi. Hipertesi atau tekanan darah tinggi merupakan suatu keadaan medis dimana ditandai dengan meningkatnya kontraksi pembuluh darah arteri sehingga terjadilah resistensi aliran darah yang meningkatkan tekanan darah terhadap dinding pembuluh darah kemudian meningkatkan kerja jantung agar bekerja lebih maksimal untuk memompa darah melalui pembuluh darah arteri yang sempit jika keadaan seperti ini dibiarkan saja maka akan menyebabkan pembuluh darah dan jantung rusak. Hipertensi sering disebut sebagai slient killer atau pembunuh diam-diam hal ini dikarenakan hipertensi sering terjadi tanpa gejala.
Seseorang dinyatakan mengidap hipertensi bila tekanan darahnya $>140 / 90 \mathrm{mmHg}$ Fauci. Et, al (2012).

Penatalaksanaan hipertensi terbagi menjadi dua yaitu, terapi farmakologis dan non farmakologis pengobatan hipertensi secara non farmakologis dapat dilakukan dengan mengubah gaya hidup yang lebih sehat salah satunya terapi merendam kaki dengan air hangat yang bertemperature $39-40^{\circ} \mathrm{C}$. Secara ilmiah air hangat mempunyai dampak fisiologis bagi tubuh pertama berdampak pada pembuluh darah dimana hangatnya air membat sirkulasi darah menjadi lancar menstabilkan aliran darah dan kerja jantung serta faktor pembebanan didalam air yang akan menguatkan otot-otot dan ligament yang mempengaruhi sendi tubuh Lalage (2015).

Rendam kaki air hangat bermanfaat untuk vasodilatasi aliran darah sehingga diharapkan dapat mengurangi hipertensi. Bertujuan untuk melancarkan 
Vol. 11 No. 022020

e-issn : 2622-0148, p-issn : 2087-0035

sirkulasi darah, relaksasi otot, menyehatkan jantung dan mengurangi edema sehingga bermanfaat untuk penurunan tekanan darah pada hipertensi Damayanti (2014).

Berdasarkan pemaparan latar belakang diatas, penulis tertarik untuk melakukan literatur riview dan mengangkat judul "Pengaruh Rendam Kaki Air Hangat Trhadap Penurunan Tekanan Darah Pada Lansia".

\section{METODE}

Dalam penulisan artikel ini menggunakan metode literature review, yaitu sebuah pencarian literature baik nasional maupun internasional yang diperoleh dari google schoolar dan Crossref. Yang dibatasi 8 tahun terakhir, dari tahun 2012 hingga 2020 dan hanya 6 jurnal yang sesuai dengan kriterian inklusi sample. Selanjutnya artikel yang dipakai sebagai sampel ini diindentifikasi dalam bentuk tabel serta dibahas secara deskriptif untuk menjelaskan metode yang ada

HASIL

Analisis kritis pada 6 artikel penelitian yang menjadi sampel dalam literatur review ini dituangkan dalam bentuk Tabel 1.

Tabel 1. Table result literature review

\begin{tabular}{|c|c|c|c|c|}
\hline No & Judul (peneliti, tahun) & $\begin{array}{c}\text { Desaign dan } \\
\text { tekhnik samplig }\end{array}$ & $\begin{array}{l}\text { Populasi dan } \\
\text { sample }\end{array}$ & Hasil \\
\hline 1. & 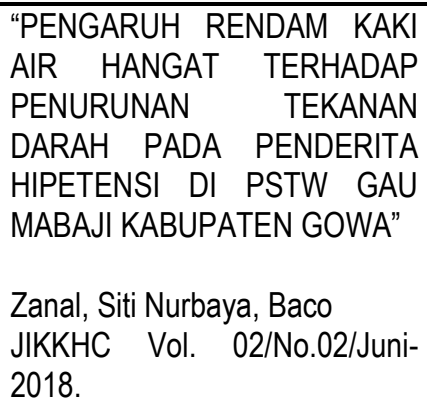 & $\begin{array}{l}\text { Pra-eksperimental } \\
\text { jenis one-group } t \text { - } \\
\text { test design }\end{array}$ & $\begin{array}{l}95 \text { orang penderita } \\
\text { hipertensi di Tresna } \\
\text { Werdha Gau Majabi } \\
\text { Kabupaten Gowa. }\end{array}$ & $\begin{array}{l}\text { Pengaruh rendam } \\
\text { kaki hangat terhadap } \\
\text { penurunan tekanan } \\
\text { darah di PSTW Gua } \\
\text { Mabaji terdapat } 0 \\
(0,0 \%) \text { penurunan } \\
\text { darah tensi normal } 10 \\
(100,0 \%)\end{array}$ \\
\hline 2. & 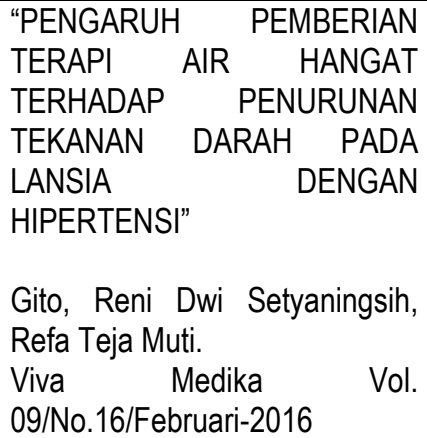 & $\begin{array}{l}\text { Simple Random } \\
\text { Sampling }\end{array}$ & $\begin{array}{l}\text { Sebanyak } \\
\text { responden }\end{array}$ & $\begin{array}{l}\text { Pembeian terapi air } \\
\text { hangat pada lansia } \\
\text { masing-masing } \\
\text { sebesar } 18 \% \text { dan } \\
21 \% \text { didominasi jenis } \\
\text { kelamin perempuan } \\
82 \%\end{array}$ \\
\hline 3. & 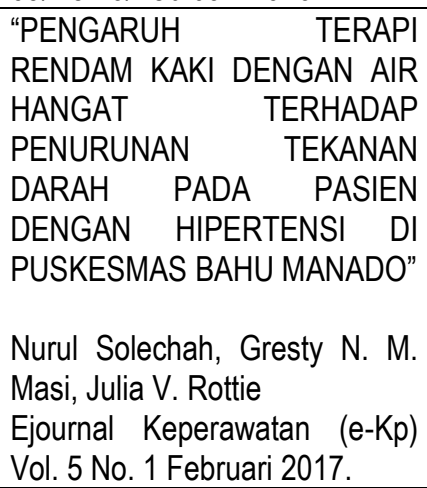 & $\begin{array}{l}\text { Non random } \\
\text { samplimg dengan } \\
\text { metode purposive } \\
\text { sampling }\end{array}$ & $\begin{array}{l}\text { Populasi penderita } \\
\text { hipertensi } \quad \text { pada } \\
\text { puskesmas } \\
\text { Bahu } \\
\text { bejumlah } 129 \text { orang }\end{array}$ & $\begin{array}{lr}\text { Hasil penelitian di } \\
\text { Puskesmas } \quad \text { Bahu } \\
\text { terdapat } & 17 \\
\text { responden } & \text { menderita } \\
\text { hipertens } & \text { dengan } \\
\text { kelompok } \quad \text { umur } \\
\text { terbanyak }>60 & \text { tahun } \\
\text { sebnayak } & 8 \\
\text { responden } & (47,1 \%) .\end{array}$ \\
\hline 4. & 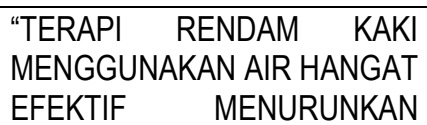 & $\begin{array}{l}\text { Penelitian } \\
\text { kuantitatif }\end{array}$ & $\begin{array}{l}\text { Pada penenlitian } \\
\text { penderita hipertensi } \\
\text { sejumlah } 20 \text { orang. }\end{array}$ & $\begin{array}{l}\text { Hasil uji } r \text { stastik } \\
\text { menunjukan } p \text {-value } \\
\text { ssitole }<0,001 \text { dan }\end{array}$ \\
\hline
\end{tabular}


Vol. 11 No. 022020

e-issn : 2622-0148, p-issn : 2087-0035

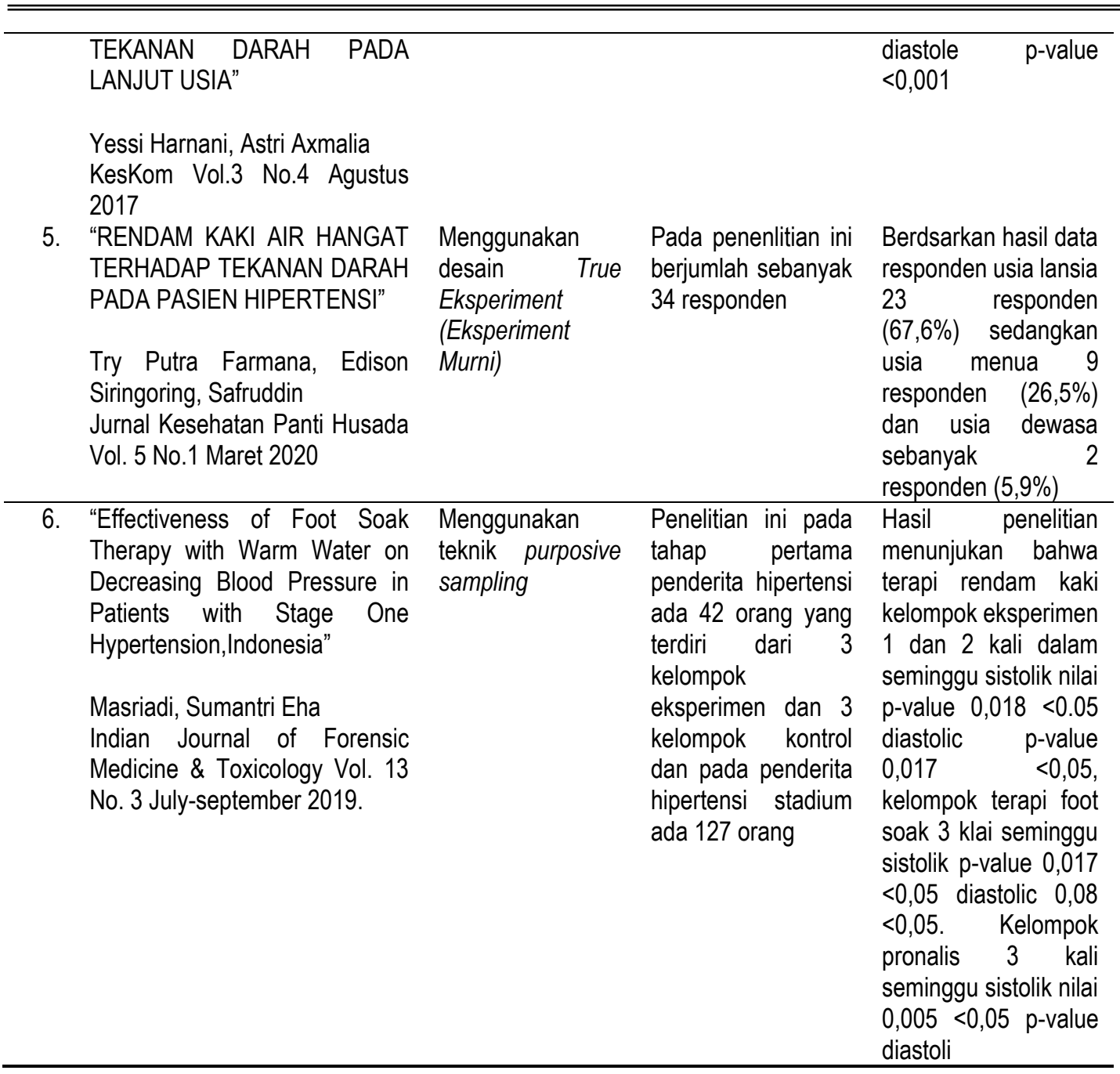

\section{PEMBAHASAN}

Hipertensi merupakan suatu keadaan dimana terjadi peningkatan tekanan darah diatas ambang batas normal. Menurut Ramadi (2015) Batas tekanan darah yang masih dianggap normal adalah kurang dari $130 / 85 \mathrm{mmHg}$ kondisi dimana tekanan darah sudah lebih dari 140/90 mmHg dinyatakan hipertensi. Santoso (2015) juga berpendapat bahwa batas normal tekanan darah adalah 120-140 mmHg tekanan sistolik dan $80-90 \mathrm{mmHg}$ tekanan diastolik seseorang dinyatakan mengidap hipertensi bila tekanan darahnya $>140 / 90 \mathrm{mmHg}$. Menurut Zuraidah, dkk (2012) Faktor yang mempengaruhi terjadinya hipertensi dibagi menjadi 2 kelompok yaitu faktor yang melekat atau tidak dapat diubah seperti jenis kelamin, umur dan genetik serta faktor yang dapat di ubah seperti pola makan dan kebiasaan olahraga. Penyebab terjadinya hipertensi perlu peran untuk faktor risiko tersebut secara bersama-sama (Common Underlying Risk Factor) dengan kata lain satu faktor risiko saja belum cukup menyebabkan timbulkan hipertensi.
Karakteristik angka kejadian hipertensi terhadap jenis kelamin menurut Malaibel (2020) sebagian besar respoden laki-laki dengan hasil 56,7\% (17 orang) disebabkan sering mengkonsumsi kopi, alkohol dan merokok dapat merangsang konstriksi pembuluh darah sehingga meningkatkan tekanan darah sedangkan responden perempuan lebih tinggi $80,0 \%$ (18 orang) dikarekanakan kurangnya hormon esterogen dapat menyebabkan penyempitan dalam pembuluh darah. Menurut Daulay (2017) berdasarkan jenis kelamin laki laki yang mengalami hipertensi $43 \%$ (7 responden) sedangkan pada responden perempuan $57 \%$ (8 responden) bahwa penderita hipertensi lebih tinggi perempuan dibandingkan dengan laki-laki. Menurut Biahimo (2020) dari hasil peneliti mengatakan bahwa laki-laki lebih berisiko mengalami hipertensi pada saat usia 45 tahun ke atas sebaliknya pada saat usia 65 tahun ke atas perempuan lebih berisiko dibandingkan laki-laki karena kondisi ini dipengaruhi oleh hormon esterogen pada perempuan yang memasuki masa menopause terjadi peningkatan tekanan darah. 
Vol. 11 No. 022020

e-issn : 2622-0148, p-issn : 2087-0035

Salah satu cara dalam menurunkan hipertensi pada lansia adalah dengan rendam kaki air hangat. Dari 6 hasil jurnal yang dianalisis menyebutkan bahwa rendam kaki merupakan metode dalam menurunkan tekanan darah. Menurut Destia dkk (2014) Merendam kaki dengan air hangat akan membuat pembuluh darah melebar dan meningkat sirkulasi darah. Ini dapat merilekskan seluruh tubuh dan mengurangi kelelahan dihari yang penuh dengan aktifitas. Prinsip kerja merendam kaki menggunakan air hangat yaitu secara konduksi dimana terjadi perpindahan panas atau hangat ke dalam tubuh dapat menyebabkan pelebaran pembuluh darah dan penurunan ketegangan otot sehingga dapat melancarkan peredaran darah sehingga akan menurukan tekanan diastolik. Menurut Umah, dkk (2012) diberikan terapi rendam kaki air hangat digunakan sebagai terapi non farmakologi dalam menurunkan tekanan darah. Terapi rendam kaki menggunakan air hangat mudah dilakukan dan dapat diberikan berbagai jenis golongan lanjut usia. Terapi ini tidak memiliki efek samping dan efektif bila dilakukan secara rutin karena terapi ini melancarkan peredaran darah. penelitian Parmana (2020) mengatakan bahwa terapi rendam kaki dengan air hangat dilakukan dengan cara merendam kaki hingga batas $10-15 \mathrm{~cm}$ diatas mata kaki secara ilmiah terapi rendam kaki air hangat dapat memperbaiki mikrosirkulasi pembuluh darah dan vasodilatasi efek rendam kaki air hangat ini menghasilkan energi kalor yang bersifat mendilatasi pembuluh darah dan melancarkan peredaran darah juga dapat merangsang saraf pada kaki untuk mengaktifkan saraf parasimpatis sehingga menurunkan tekanan darah yang tinggi.

Berdasarkan hasil dari penelitian jurnal yang ditemukan, didapatkan hasil rata-rata tekanan darah sebelum dilakukan terapi rendam kaki air hangat sistoliknya $160 \mathrm{mmHg}$ dan rata-rata tekanan darah diastoliknya $100 \mathrm{mmHg}$. Setelah dilakukan terapi rendam kaki air hangat ini rata-rata tekanan darahnya mengalami penurunan sistoliknya menjadi $150 \mathrm{mmHg}$ serta diastoliknya $90 \mathrm{mmHg}$ (Khoiro, 2014). Sejalan dengan penelitian yang dilakukan oleh Jiang et al (2016) yang berjudul komposisi pengobatan tiongkok dan metode aplikasi untuk pengobatan eksternal hipertensi 1 responden yang menderita hipertensi selama 14 tahun terakhir dengan tekanan darah $145 / 90 \mathrm{mmHg}$ serta dokter menyarankan agar dia minum obat tetapi dengan mengingat usianya yang sudah lansia memutuskan untuk mencoba metode pengobatan ringan dengan terapi rendam kaki air hangat setiap hari selama 20-30 menit kemudia di ukur tekanan darahnya. Setelah dalam 1 minggu tekanan darahnya menjadi menurun. Terapi ini dilakukan selama 3 kali dalam seharinya sehingga tekanan darahnya menjadi $130 / 80 \mathrm{mmHg}$.

Kelebihan terapi rendam kaki air hangat ini menurut Lantera (2017) mengatakan bahwa dapat memperbaiki mikrosirkulasi pembuluh darah dan vasodilatasi serta menghasilkan energi kalor yang bersifat mendilatasi pembuluh darah serta dapat merangsang saraf pada kaki mengaktifkan saraf parasimpatis. Dewi (2015) menyatakan bahwa rendam kaki air hangat ini ada efek terapeutik untuk mengurangi tekanan darah pada lansia. Menurut Guyton (2016) kelebihan dalam terapi rendam kaki air hangat memang terbukti berpengaruh pada lansia yang mengalami hipertensi dikarenakan responden selalu melaksanakan yang diinstruksikan oleh penenliti sehingga pemberian terapi rendam kaki air hangat dengan hasil maksimal serta terbukti dengan hasil tekanan darahnya turun $130 / 80 \mathrm{mmHg}$. Serta menurut Yahya Prananda (2017) mengatakan kelebihan terapi ini untuk meningkatkan sirkulasi darah menguragni edema, relaksasi otot menjadi menyehatkan jantung, menghilangkan setres serta meringangkan kekakuan otot.

Kekurangan terapi rendam kaki air hangat menurut Perry \& Potter (2015) adalah jika responden mengalami kondisi tekanan darah yang sudah memburuk serta kurangnya kerja sama antara responden dan peneliti sehingga terkadang pemberian terapi rendam kaki air hangat tidak berjalan sesuai prosedur.

Menurut beberapa jurnal dan artikel yang dianalisis beberapa peneliti mengatakan bahwa rendam kaki air hangat dapat menurunkan tekanan darah pada golongan lanjut usia. Rendam kaki air hangat ini jika dilakukan dengan rutin 3 kali sehari dalam merendam kaki dengan waktu 20-30 menit 1-5 $\mathrm{cm}$ di atas mata kaki maka dapat menurunkan tekanan darahnya dengan jangka 1 minggu dan menurut hasil dari beberapa jurnal terdapat responden perempuan yang paling tinggi terkena hipertensi di bandingkan dengan responden laki laki dikarenakan pada responden perempuan pengaruhnya pada kekurangan hormon esterogen menyebabkan penyempitan dalam pembuluh darah sedangkan pada responden laki-laki pengaruhnya pada sering mengkonsumsi kopi, rokok dan alkohol yang menyebabkan hipertensi. Serta rendam kaki air hangat ini juga dapat merilekskan tubuh ketika seharian melakukan aktivitas.

\section{KESIMPULAN}

Adapun kesimpulan dari penulisan literature review ini adalah rendam kaki air hangat digunakan sebagai metode dalam menurunkan tekanan darah terhadap lansia. Selain dapat digunakan sebagai merilekskan otot-otot serta persendian setelah melakukan aktivitas setiap harinya. Rendam kaki air hangat ini dilakukan 3 kali dalam setiap harinya dengan waktu 20-30 menit bagi lansia yang tekanan darahnya berstadium. 


\section{DAFTAR PUSTAKA}

Zaenal, Z. (2018). Pengaruh Rendam Kaki Air Hangat Terhadap Penurunan Teknan Darah Pada Penderita Hipertensi Di PSTW Gau Mabaji Kabupaten Gowa. Jurnal Ilmiah Keperawatan dan Kebidanan Holistic Care, 2(02), 156-161.

Destia, dkk (2014). Perbedaan Tekanan Darah Sebelum Dan Sesudah Dilakukan Hidroterapi Rendam Air Hangat Pada Penderita Hipertensi di Desa Kebondalem Kecamatan Jambu Kabupaten Semarang. Jurnal STIKES Ngudi Waluyo Ungaran 2014. 4-9

Jiang et, al (2016), Dewi, (2015). Effectiveness of Foot Soak Therapy with Warm Water on Decreasing Blood Pressure in Patients with Stage One Hypertension,Indonesi. Indian Journal of Forensic Medicine \& Toxicology Vol. 13 No. 3 July-september 2019.

Khoiro, (2014). Pengaruh Rendam Kaki dengan Air Hangat Terhadap Penurunan Tekanan Darah Pada Hipertensi. Journal of Ners Community. ISSN 2087-0744,3(6) 72-82.

Ramadi, (2012), Zuraidah, dkk, (2012). Pengaruh Pemberian Terapi Air Hangat Terhadap Penurunan Tekanan Darah Pada Lansia Dengan Hiperensi. Viva Medika, Vol. 09 No. 16 Feb 2016

Umah, dkk, (2012). Terapi Rendam Kaki Menggunakan Air Hangat Efektif Menurunkan Tekanan Darah Pada Lanjut Usia. Keskom, Vol. 3 No. 4 Agustus 2017

Lantera, (2017), Purnawan, (2015), Parmana (2020). Rendam Kaki Air Hangat Terhadap Tekanan Darah Pada Pasien Hipertensi. Jurnal Kesehatan Husada, Vol. 5 No. 1 Maret 2020

Guyton, (2016), Perry \& Potter, (2015). Pengaruh Terapi Rendam Kaki Air Hangat Terhadap Perubahan Tekanan Darah Pada Penderita Hipertensi. Journal Of Ners Community, Vol. 3. No. 6 Februari 2019

Yahya Prananda, (2017) Pengaruh Pemberian Rendam Kaki Air Hangat Terhadap Penurunan Tekanan Darah Pada Lansia Dengan Hipertensi Di Wilayah Kerja Puskesmas Rasau Jaya Kabupaten Kubu Raya. 2017.

Malaibel (2020). Pengaruh Pemberian Hidroterapi (Rendam Kaki Air Hangat) Terhadap Penurunan Tekanan Darah Pada Pasien Hipertensi Di Wilayah Kerja Puskesmas Sikumana Kota Kupang. CHMK Health Journal. 2020, 4(1), 124-131.

Daulay, N. M \& Simamora, F. A. (2017). Pengaruh Rendam Kaki Dengan Air Hangat Terhadap Penurunan Tekanan Darah Pada Penderita Hipertensi Di Kelurah Timbangan Tahun 2017. Jurnal Kesehatan IImiah Indonesia (Indonesia Health Scientific Journal), 2(3), 57-67.

Biahimo, N. U. I. (2020). Perubahan Tekanan Darah Lansia Melalui Terapi Rendam Kaki Menggunakan Air Hangat. Jakiyah: Jurnal IImiah Umum dan Kesehatan Aisyiyah, 5(1), 9-16. 